\title{
A SEGURANÇA ALIMENTAR E OS MODELOS DE PRODUÇÃO AGRÁRIA QUÍMICO-DEPENDENTES
}

\author{
Maurício Pedroso Flores ${ }^{1}$ \\ Matheus Silva De Gregori ${ }^{2}$ \\ Luiz Ernani Bonesso de Araujo ${ }^{3}$
}

\begin{abstract}
RESUMO
Este trabalho teve como objetivo avaliar os impactos do atual modelo de produção agrícola, relacionando-o com o tema da segurança alimentar. Ponderaram-se, além dos efeitos meramente econômicos, os aspectos sociais e ambientais afetados pelo fomento da agricultura químico-dependente. Constata-se que o desenvolvimento do setor agrário não acarreta em uma distribuição mais equitativa da produção, nem mesmo na qualidade dos alimentos disponibilizados à população. Verificou-se, a partir de um método de abordagem sistêmico-complexo, que a lógica do mercado reduz o poder dos pequenos agricultores, que são dominados pela monopolização da produção, regularizada pelos lobbys empresariais. Ressalta-se a importância da análise profunda do tema, indicando a possibilidade de uma economia rural mais solidária e participativa, a partir de uma repolitização e reestruturação dos modos de produção.
\end{abstract}

Palavras-chave: Produção. Agricultura. Químico-dependentes. Alimentos.

\section{INTRODUÇÃO}

No contexto das preocupações ambientais que invadiram a agenda política dos governos nas últimas décadas, a segurança alimentar aparece com uma questão não apenas de cunho ecológico, mas que também se insere no rol dos direitos humanos fundamentais. A problemática que envolve a distribuição e a qualidade dos alimentos tem sido vista com cuidado por profissionais e pesquisadores, bem como por parte dos órgãos públicos responsáveis.

Com efeito, a Lei $\mathrm{n}^{\circ} 11.346$, de 15 de setembro de 2006, estabeleceu a criação de um sistema governamental específico para as questões de segurança alimentar - o SISAN (Sistema Nacional de Segurança Alimentar e Nutricional). Por meio deste, o poder público, em conjunto com a sociedade civil, procura formular e implantar "políticas, planos, programas e ações com vistas em assegurar o direito humano à alimentação adequada.” (BRASIL, 2006)

\footnotetext{
${ }^{1}$ Autor. Acadêmico do Curso de Direito da Universidade Federal de Santa Maria (UFSM). Bolsista FIPEUFSM. Integrante do Grupo de Pesquisa em Direito da Sociobiodiversidade (GPDS/UFSM). E-mail: mauriciopflores@gmail.com

${ }^{2}$ Coautor. Acadêmico do Curso de Direito da Universidade Federal de Santa Maria (UFSM). Bolsista PIBIC/Cnpq. Integrante do Grupo de Pesquisa em Direito da Sociobiodiversidade (GPDS/UFSM). Email: matheus.gregori@hotmail.com

${ }^{3}$ Orientador. Doutor em Direito, Professor de Direito Agrário e Ambiental e Chefe de Departamento do Curso de Direito da Universidade Federal de Santa Maria (UFSM). Pesquisador do Grupo de Pesquisa em Direito da Sociobiodiversidade (GPDS/UFSM).
} 
Entre as questões abrangidas pela referida lei estão a ampliação do acesso à alimentação, a utilização sustentável dos recursos naturais e a garantia da qualidade biológica dos alimentos. Procura-se, dessa forma, uma análise interdisciplinar que une concepções frequentemente ignoradas pelos produtores do grande mercado de alimentos, como a proteção da biodiversidade e do solo.

No caso da produção agrícola de commodities, voltada ao mercado externo, comumente se exerce uma atividade predatória em relação à natureza, pautada pela mesma lógica de crescimento que se verifica no sistema industrial urbano. Um dos principais meios utilizados para o aumento constante da produção alimentícia é o uso constante de agrotóxicos, alguns deles sabidamente prejudiciais, mas legalmente permitidos. A legislação vigente nessa questão é a do Decreto $n^{\circ} 4.074$, de 2002, que regulamentou a Lei no 7.082/89, a chamada Lei dos Agrotóxicos. Por ir de encontro aos interesses de grandes monopólios do setor, sua aplicação torna-se por vezes difícil.

Além do processo químico-dependente de produção, a lógica de apropriação de terras e o avanço das fronteiras agrícolas se colocam como problemas urgentes de cunho social e ambiental. A agricultura voltada à exportação, baseada no antigo sistema latifundiário, configura-se como ameaça à segurança alimentar na medida em que não se importa com a qualidade alimentícia nem com a distribuição equitativa da produção.

A produção de alimentos saudáveis para a população confronta-se ainda com outras espécies de cultivo, voltadas aos interesses dos mercados mundiais de agrocombustíveis. Culturas como a soja e o eucalipto têm crescido imoderadamente nas terras agricultáveis em detrimento de outras culturas cuja demanda é maior no mercado interno. Por demandarem grandes quantidades de agrotóxicos, esses produtos carregam também um enorme risco de contaminação para os demais.

\section{A questão espacial}

Defender as questões relativas à segurança alimentar não significa, por óbvio, somente prezar pela qualidade dos alimentos produzidos. Em tempos globalizados, fazse imperiosa uma análise geral das estruturas institucionais e as condições em que se dão as interações sociais. Em se tratando de tema relativo à atividade rural, é necessário levar-se em conta todo o histórico de lutas por terra e de violência no campo, algo que 
ocorre especialmente nos chamados países em desenvolvimento, não sendo, definitivamente, exclusividade do Brasil.

No caso específico do nosso país, uma breve análise histórica ajuda a explicar porque o Brasil é o maior consumidor de agrotóxicos do mundo, mesmo não sendo o maior produtor agrícola mundial. ${ }^{4}$ Nas últimas décadas, a agricultura brasileira assistiu um proliferar de máquinas, implementos e outras tecnologias agrícolas, que colocaram o Brasil como um dos grandes países do mercado global do agronegócio.

Com forte presença de traços da globalização econômica, operou-se uma enorme mudança estrutural nas relações de espaço, emprego de mão-de-obra e de comércio de alimentos, tanto no mercado interno como em relação às exportações. Tal progresso, no entanto, longe de refletir um progresso nas bases socioeconômicas do Estado, foi alavancado pelas forças de mercado promotoras do crescimento econômico. Esse desenvolvimento, contudo,

[...] traz, mesmo quando bem-sucedido em nível econômico, resultados sociais opostos aos almejados: as diferenças sociais aumentam, a riqueza se concentra na mão de uma minoria, com marginalização simultânea de uma parcela importante da população. (SACHS, 2008, p.118)

Aliado ao fenômeno da desindustrialização ocorrido na década de 90, o crescimento do agronegócio recolocou o país no papel de economia primária, no contexto de uma nova divisão internacional do trabalho que passou a ser liderada pelo industrialismo emergente da China.

Esse modelo primário e exportador contribuiu para solapar a agricultura familiar e acentuar os conflitos rurais. A ideia de um crescimento puxado pela geração de empregos não foi sequer considerada no desenvolvimento agrícola brasileiro. Ao invés de uma distribuição mais equitativa de terras - o antigo ideal da reforma agrária, que hoje encontra seu último refúgio nos movimentos sociais - esse desenvolvimento proporcionou aos agentes de mercado a oportunidade de dominar o cerne das atividades econômicas também no campo.

Além disso, a industrialização do modelo agrícola impeliu a idéia de que o melhoramento e a produção das variedades deveriam ser manejados apenas por

\footnotetext{
${ }^{4}$ Como refere Bombardi (2011, p.71), o Brasil alcançou o primeiro lugar no ranking mundial de agrotóxicos no ano de 2009.
} 
profissionais especializados, "legitimados" pela ciência (engenheiros agrônomos, fitogeneticistas, biólogos, etc.). Desta sorte, como aduz Santilli (2009, p.136-137):

\begin{abstract}
Os agricultores passaram a ser tratados como simples produtores agrícolas e consumidores de sementes. [...] Trata-se de uma concepção que negou o papel dos agricultores como inovadores e detentores de saberes e práticas fundamentais para os sistemas agrícolas e para a manutenção da agrobiodiversidade.
\end{abstract}

A modernização agrícola teve por meios o crescimento do número de latifúndios produtores de culturas de exportação (especialmente a soja), o uso excessivo de agrotóxicos para sustentar a dependência química das culturas e o avanço sobre as fronteiras naturais de mata. Competir com os grandes produtores agrícolas, mesmo que nos mercados locais, constitui-se hoje em tarefa inglória para os pequenos agricultores. As associações destes, antes fóruns de debates sobre questões como preços e troca de sementes crioulas, transformaram-se em verdadeiros núcleos de resistência contra a dominação de conglomerados empresariais, como a Monsanto e a Bayer.

O modelo de produção agrária atualmente hegemônico no Brasil está marcado pela entrada do capitalismo no campo e pela chamada "revolução verde" que lhe dá sustentação, tendo um caráter perverso em relação ao modo de apropriação / exploração / expropriação da natureza e da força de trabalho. O agrotóxico é uma expressão de seu potencial morbígeno e mortífero, que transforma os recursos públicos e os bens naturais em janelas de negócios. (CARNEIRO et al, 2012b, p.17)

$\mathrm{Na}$ primeira parte de um dossiê sobre questões de segurança alimentar, publicado em abril de 2012, a ABRASCO (Associação Brasileira de Saúde Coletiva) expressou o atual contexto como "de reprimarização da economia, da expansão das fronteiras agrícolas para a exportação de commodities, da afirmação do modelo da modernização agrícola conservadora e da monocultura químico-dependente.” (CARNEIRO et al, 2012a, p.11)

Como demonstram as estatísticas a respeito do uso de agrotóxicos ${ }^{5}$, o agronegócio não demonstra grandes preocupações com a segurança alimentar dos consumidores ou com a saúde daqueles que trabalham ou moram próximo às lavouras.

${ }^{5}$ Somente em 2010, por exemplo, o Brasil utilizou 923 milhões de litros de pesticidas em suas lavouras. 
Dentre os vários impactos dessa cadeia produtiva, os de maior relevância para a saúde e ambiente são as poluições e intoxicações agudas e crônicas relacionadas aos agrotóxicos. Neste processo agroquímico dependente, os fazendeiros contaminam de modo intencional a lavoura, o produto, o ambiente, os trabalhadores rurais e a população do entorno, com o objetivo de atingir o alvo, ou seja, as "pragas" da lavoura (inseto, fungo ou erva daninha). Trata-se de um processo crítico para a saúde-ambiente e que pode ser definido como poluição intencional por agrotóxicos e não como acidente ou "deriva" que culpabiliza o clima ou o pulverizador. (PIGNATI et.al., 2011, p. 66)

Por conta dessas ameaças à saúde, muitas vezes indivíduos são forçados a deixarem o local onde tradicionalmente viviam. Ao êxodo rural, fenômeno característico do século passado em quase todos os estados brasileiros, soma-se também a questão dos povos tradicionais, sobretudo indígenas, que veem seus direitos de propriedade desrespeitados frente ao avanço das fronteiras agrícolas. Os conflitos em torno das reservas legais tornaram-se ainda mais frequentes nas últimas décadas, marcadas pelo progresso da modernização agrícola.

\section{As questões de consumo}

Frequentemente, os promotores da agricultura transgênica justificam sua atividade predatória com o argumento da necessidade de aumento da produção mundial de alimentos - do contrário, não haverá provimentos suficientes para alimentar a população mundial. Mesmo diante dos riscos de se consumir alimentos produzidos a base de agrotóxicos ou geneticamente modificados, os defensores modernos da Revolução Verde ${ }^{6}$ nos dizem que, sem considerar tais riscos, seria impossível manter a produção alimentícia nos níveis atuais.

O dilema entre o aumento da produção agrícola, mesmo que com ameaças à saúde, e o aumento da fome, causado pela falta de alimentos disponíveis é, no entanto, sabidamente falso. O problema da distribuição desigual sempre se sobrepôs ao da

\footnotetext{
${ }^{6}$ Revolução Verde é um termo empregado para o contexto de disseminação de novas sementes e práticas agrícolas ocorrido nos países menos desenvolvidos durante as décadas de 60 e 70 . As iniciativas de uso intensivo de tecnologia no campo - organismos geneticamente modificados, insumos agrícolas, pesticidas, mecanização etc. - provocaram um grande aumento na produção de alimentos nos países em que a Revolução Verde operou-se. Brasil e Índia, que posteriormente passaram a desenvolver suas próprias tecnologias, foram dois grandes beneficiados.
} 
III SEMINÁRID ECDLDGIA

produção global. Apesar das contínuas quebras de recorde das safras anuais, a fome e a miséria aparecem como uma ferida aberta e aparentemente sem solução dentro do atual sistema capitalista. Como afirma Seabrook (1998 apud BAUMAN, 1999, p.87) isso se explica pelo fato de que "a pobreza não pode ser 'curada', pois não é um sintoma da doença do capitalismo. Bem ao contrário: é evidencia da sua saúde e robustez, do seu ímpeto para uma acumulação e esforço sempre maiores."

\subsection{Os lobbys empresariais}

Há de se ressaltar, em meio à procura constante pelo aumento da produção agrícola, a existência de instrumentos legislativos que regulam a circulação de produtos potencialmente nocivos à saúde. São inúmeros os casos de substâncias largamente utilizadas nas lavouras que foram posteriormente proibidas em diversos países. O DDT, proibido nos EUA na década de 70, é um dos exemplos mais notáveis. ${ }^{7}$ Muitos outros pesticidas seguiram o mesmo caminho em diversos países, que, além de provarem a nocividade dos produtos à saúde humana, conseguiram impor legislações proibitivas contrariamente os interesses de grandes empresas do ramo.

Em relação ao Brasil, a ANVISA (Agência Nacional de Vigilância Sanitária), aponta que "dos 50 agrotóxicos mais utilizados nas lavouras de nosso país, 22 são proibidos na União Europeia" (CARNEIRO et al, 2012a, p. 20) ${ }^{8}$, o que denota certo atraso em relação as pesquisas sobre os malefícios desses produtos e/ou a influência de grupos empresariais na defesa de seus lucros no setor. O lobby empresarial sobre as agências governamentais e membros do poder Legislativo não é fenômeno recente, já sendo tema de diversas polêmicas nas mais diversas áreas.

\footnotetext{
7 "No Brasil, o DDT teve sua retirada do mercado em duas etapas: em 1985, quando sua autorização foi cancelada para uso agrícola; e em 1998, sendo proibido para uso em campanhas de saúde pública. Finalmente, em 2009, teve seu banimento definitivo. Através da Lei 11.936/2009, ficou proibida a fabricação, a importação, a exportação, a manutenção em estoque, a comercialização e o uso de DDT no país." (CARNEIRO et al, 2012b, p.17)

8 "Na ANVISA estão em processo de revisão, desde 2008, 14 agrotóxicos: cinco deles já foram proibidos (acefato, cihexatina e tricloform), sendo que o metamidofós será retirado do mercado a partir de junho de 2012, e o endossulfama partir de junho de 2013." (CARNEIRO et al, 2012a , p.20)
} 
como o aumento da produção para que todos possam ter acesso à alimentação, o que as empresas de biotecnologia costumam almejar é um domínio sobre os produtores, colocando-os em um regime praticamente servil.

\subsection{Consequências de uma agricultura químico-dependente}

O modelo agrário atualmente hegemônico no Brasil alimenta-se de um ciclo vicioso que envolve sementes transgênicas e pesticidas. As preocupações com a alimentação sadia e a distribuição justa da riqueza produzida no campo parecem estar cada vez mais fora desse ciclo. A agricultura químico-dependente monopoliza os debates - respondendo tudo de acordo com os argumentos da biotecnologia - e dificulta a procura por saídas ao modo de produção vigente.

Além de monopolizar a produção de sementes, a Monsanto, por exemplo, cobra royalties dos agricultores pelo seu uso, como no caso da soja transgênica. Esse sistema, viciado numa distribuição desigual da riqueza produzida, só encontra barreiras nas ações conjuntas de movimentos rurais, o que pressupõe, para que exista o apoio dos demais setores sociais, o acesso à informação sobre os prejuízos da agricultura transgênica.

Verdadeira batalha judicial se desenrola no Rio Grande do Sul, onde um grupo de produtores alega a alta contaminação da soja transgênica sobre a não-transgênica, o que dificulta sua separação, exigida pela Monsanto. Como a empresa penaliza o agricultor em $3 \%$ no carregamento de soja supostamente não modificada que contiver soja transgênica, o chamado "Imposto Monsanto" mostra-se absolutamente injusto. Em abril desse ano, um juiz gaúcho ordenou que a empresa deixasse de cobrar royalties e devolva valores cobrados dos agricultores, que chegam a 2 bilhões de dólares. ${ }^{11}$

Uma saída possível a esse modelo explorador da terra e do agricultor é a agricultura orgânica, diretamente associada aos ideais do desenvolvimento sustentável, mas que encontra diversas adversidades em seu processo de expansão. O principal deles

\footnotetext{
11 “A Monsanto está apelando da decisão, mas recebeu outro golpe no dia 12 de junho, quando o Supremo Tribunal Federal determinou de forma unânime que a decisão do judiciário do Rio Grande do Sul seja abrangente ao país inteiro. Isso aumenta o montante envolvido para 7,5 bilhões de dólares. Agora, os agricultores que processam a Monsanto são cinco milhões. Em uma declaração concisa, a Monsanto declarou que seguirá cobrando os royalties dos agricultores brasileiros até que o caso se resolva em definitivo.” (MARRERO, 2012)
} 
é a dificuldade em se competir com os produtos não orgânicos no mercado interno, pois estes são na maioria das vezes mais baratos. $\mathrm{O}$ alto preço dos alimentos orgânicos se explica pela dificuldade em manter padrões de cultivo orgânico em larga escala, tanto por questões de terra como de empreendedorismo. ${ }^{12}$

\section{CONSIDERAÇÕES FINAIS}

No atual contexto de desindustrialização vivido pelo Brasil na última década, a economia primária tem se destacado como o propulsor do desenvolvimento econômico do país. Seu processo produtivo, contudo, não atenta para questões sociais como o direito a uma alimentação saudável. A agricultura químico-dependente - cujos lucros sustentam o aumento do poder econômico das grandes empresas multinacionais que dominam o ramo - vem restringindo as possibilidades de se tratar questões relativas à concentração de terra no campo e à qualidade dos alimentos produzidos, sobretudo para o mercado interno.

O consumo excessivo de agrotóxicos é uma ameaça real que paira não apenas sobre os cultivos transgênicos, mas sobre todas as culturas em geral, dado o elevado grau de contaminação dos pesticidas e dos organismos geneticamente modificados. Enquanto o atual modelo de produção de commodities permanecer inalterado, os riscos à saúde dos consumidores dificilmente serão reduzidos. Para uma mudança do atual paradigma monocultor, faz-se necessário repensar o modelo agrícola, agregando os ideais da sustentabilidade em suas práticas - e não adotando o falho discurso da Economia Verde, que desconsidera a multidimensionalidade da concepção de desenvolvimento. $^{13}$

Decisões judiciais contrárias aos interesses do monopólio empresarial instituídos nas áreas de biotecnologia fomentam a esperança de uma economia rural mais solidária e participativa. A produção de alimentos, nesse modelo, não obedeceria a uma lógica desarrazoada de crescimento econômico, bem como de aumentos injustificados da produção, com vistas à mera especulação de preço nos mercados internacionais.

\footnotetext{
${ }^{12}$ Nesse aspecto, cabe a ressaltar a escassez de políticas e iniciativas, por parte dos governos, que visem apoiar a produção orgânica, seja por meio de empréstimos aos produtos ou de isenções fiscais.

${ }^{13}$ Sachs (2008, p.118) aponta para "uma estratégia de desenvolvimento que seja ambientalmente sustentável, economicamente sustentada e socialmente includente." Essa abordagem representa a noção de um desenvolvimento real, que agrega valores - não apenas econômicos - à sociedade.
} 


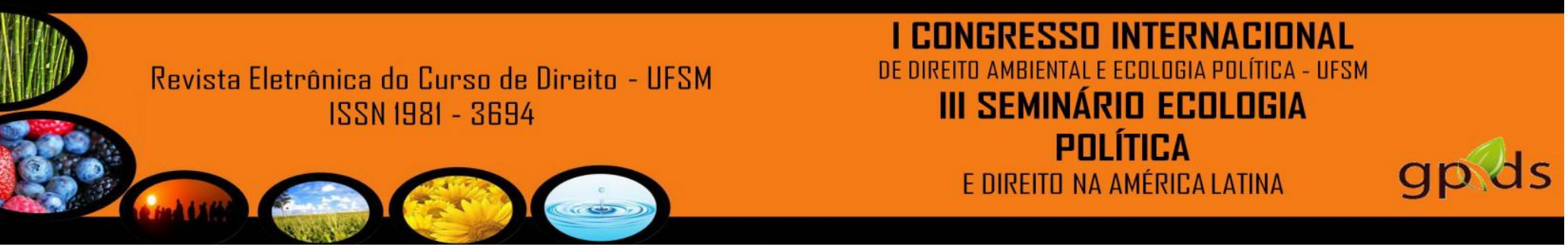

A preocupação com a segurança alimentar e a reestruturação dos modos de produção de forma mais equitativa devem estar intimamente ligadas, completando-se e cooperando para um desenvolvimento sustentável. Garantir alimentos sadios na mesa dos cidadãos não é uma proposta que se desvincule das questões sociais e políticas - ao contrário, é justamente um compromisso de libertação do modelo químico-dependente que divide lucros para alguns e multiplica prejuízos para todos.

\section{REFERÊNCIAS BIBLIOGRÁFICAS}

BAUMAN, Zygmunt. Globalização: as consequências humanas. Rio de Janeiro: Jorge Zahar Ed., 1999.

BOMBARDI, Larissa Mies. A intoxicação por agrotóxicos no Brasil e a violação dos direitos humanos. In: Merlino, Tatiana; Mendonça, Maria Luisa. (Org.). Direitos Humanos no Brasil 2011: Relatório. São Paulo: Rede Social de Justiça e Direitos Humanos, 2011, p. 71-82.

BRASIL. Lei $\mathrm{n}^{\circ}$ 11.346, de 15 de setembro de 2006. Cria o Sistema Nacional de Segurança Alimentar e Nutricional - SISAN. Diário Oficial [da] República Federativa do Brasil, Brasília, DF, 15 set. 2006. Disponível em: <http://www.planalto.gov.br/ccivil_03/_ato2004-2006/2006/lei/111346.htm>. Acesso em: 28 ago. 2012.

CARNEIRO, Fernando. et al. (2012a) Dossiê ABRASCO - Um alerta sobre os impactos dos agrotóxicos na saúde. ABRASCO, Rio de Janeiro, abril de 2012. $1^{\text {a }}$ Parte. 98p.

CARNEIRO, Fernando. et al. (2012b) Dossiê ABRASCO - Um alerta sobre os impactos dos agrotóxicos na saúde. ABRASCO, Rio de Janeiro, junho de 2012. $2^{\text {a }}$ Parte. 135p.

COHEN, Robert. Leite - Alimento ou Veneno? São Paulo: Ground, 2005.

MARRERO, Carmelo Ruiz. Brasil: Monsanto em apuros. Brasil de Fato. São Paulo, 30 jul. 2012. Disponível em: 〈http://www.brasildefato.com.br/node/10214〉. Acesso em: $1^{\circ}$ set. 2012.

PIGNATI, Wanderlei. et al. O agronegócio e os impactos dos agrotóxicos na saúde e ambiente: produtividade ou caso grave de saúde pública? In: Merlino, Tatiana; Mendonça, Maria Luisa. (Org.). Direitos Humanos no Brasil 2011: Relatório. São Paulo: Rede Social de Justiça e Direitos Humanos, 2011, p. 65-69. 


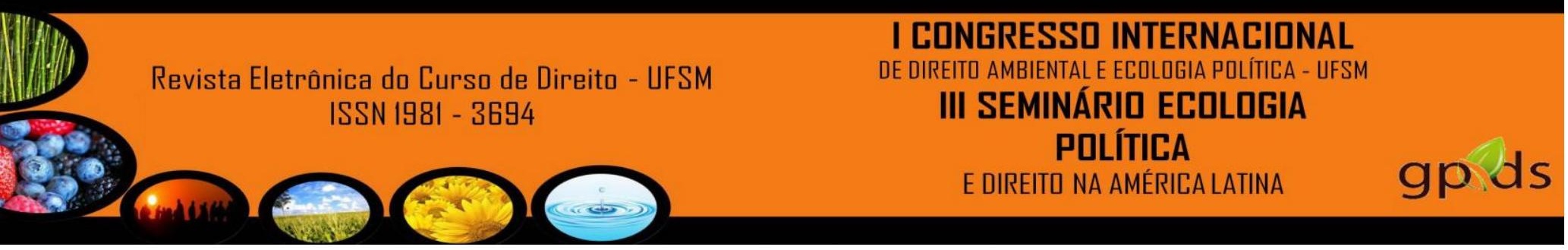

SANTILLI, Juliana. Agrobiodiversidade e Direitos dos Agricultores. Editora Peiropolis, Brasil: 2009. 520p.

SACHS, Ignacy. Desenvolvimento includente, sustentável, sustentado. Rio de Janeiro: Garamond, 2008. 